\title{
A recepção e produção de sentido sobre os espaços urbanos: olhares dos acadêmicos de cinema da UFPel
}

Fábio Souza da Cruz / Guilherme Carvalho da Rosa

\section{Resumo:}

A pesquisa apresentada está em andamento e traz como objeto a observação das circunstâncias de recepção e produção de um documentário sobre espaços urbanos produzido por acadêmicos de cinema da Universidade Federal de Pelotas/RS (UFPel). O olhar teórico-metodológico está voltado para dois momentos. O primeiro é o da recepção desses espaços sobre a ótica das interculturalidades (GARCÍA CANCLINI, 2006) e da reconfiguração dos sentidos da vida urbana (MARTÍN-BARBERO, 2005). O segundo é o da produção do documentário, por meio das estruturas de sentido dos estudantes interpeladas por suas experiências urbanas cotidianas. O objetivo central é observar como as práticas culturais estão articuladas com os espaços urbanos, a partir da vivência de temporalidades agonísticas na América Latina.

\section{Palavras Chave:}

recepção e produção; espaços urbanos; estudos culturais.

\section{Abstract:}

This in progress research analyzes the circumstances of reception and production of a documentary about urban spaces. The documentary was produced by film students from the Federal University of Pelotas/RS (UFPel). A theoretical and methodological overview is dedicated to these two moments of reception - through the perspective of interculturality (Garcia Canclini, 2006) and reconfiguration of urban life meanings (Martin-Barbero, 2005) - and production - considering the contact of the students' meaning structures and their everyday urban experiences. This article observes how cultural practices are articulated with urban spaces, based on urban experiences in Latin America.

\section{Keywords:}

reception and production; urban spaces; cultural studies.

\section{Introdução}

A investigação que propomos aqui acompanha uma das preocupações centrais de determinadas agendas de pesquisa em comunicação, sobretudo as que se dedicam a observar as relações de comunicação e cultura. Trata-se do desafio de pensar a circulação da cultura e a produção de sentidos sobre a cidade em um tempo de crise da modernidade. $\mathrm{O}$ espaço urbano torna-se um grande palco de conflito das estruturas da modernidade com suas próprias certezas: mudam-se os modos de estar na cidade e as maneiras de se produzir sentido sobre ela. Tal como uma das grandes narrativas do moderno, a cidade também sofre um processo de deslegitimação (LYOTARD, 2004) e esfalecimento de suas certezas.

Esse panorama agonístico torna-se ainda mais complexo quando procuramos pensar as cidades no espaço cultural latino-americano por conta de considerarmos o descompasso temporal historicamente construído e 
que exime a considerar desajustes e lapsos do passado ao mesmo tempo em que se dialoga com a condição pós-moderna. Essa breve preocupação teórica está presente como motivação do trabalho que se destina a observar as circunstâncias de recepção e produção de sentido a partir de um documentário produzido por alunos do curso de cinema e animação da Universidade Federal de Pelotas (UFPel) no Rio Grande do Sul. O documentário, chamado Olhares, é resultado de um projeto de extensão realizado com os alunos e a primeira produção audiovisual do curso que foi inaugurado em 2007. A produção é composta de recortes sobre os espaços urbanos de Pelotas a partir da perspectiva dos próprios estudantes. Foram 13 relatos e cada acadêmico pôde escolher um espaço específico da cidade e retratá-lo com um depoimento e imagens. Mesmo considerando o próprio documentário como motivador deste estudo, nosso interesse de pesquisa não residirá na observação do texto midiático. Para essa definição, faremos uso da trajetória dos estudos culturais, especialmente a partir da contribuição de Richard Johnson (2004: 35), que considera a perspectiva de produção, circulação e consumo de produtos culturais e estabelece quatro momentos interconectados para esta dinâmica: produção, texto, recepção e culturas vividas. Mesmo pensando especificidades para cada um dos momentos, Johnson pensa o diagrama de circulação da cultura como uma relação de interdependência:

Cada momento depende dos outros e é indispensável para o todo. Cada um deles, entretanto, é distinto e envolve mudanças características de forma. (...) Todos os produtos culturais, por exemplo, exigem ser produzidos, mas as condições de sua produção não podem ser inferidas simplesmente examinandoos como "textos". (...) Para compreender as transformações, pois, nós temos que entender as condições específicas do consumo e da leitura. Essas incluem simetrias de recursos e de poder materiais e culturais. Também incluem os ensembles existentes de elementos culturais já ativos no interior de milieux sociais particulares ("culturas vividas", no diagrama) e as relações sociais das quais essas combinações dependem. (JOHNSON, 2004: 33 e 34)

Com esse ponto de partida, localizamos o interesse desta pesquisa em dois momentos específicos, interconectados pelas relações culturais: (1) o momento da recepção dos espaços urbanos e, a partir daí, a problematização da experiência sobre a cidade, levando em conta tanto o panorama agonístico do pósmoderno quanto a perspectiva das interculturalidades e (2) o momento de produção do texto midiático e das imagens sobre os espaços urbanos, interpelado a partir das estruturas de sentido e repertórios culturais e estéticos dos acadêmicos. A idéia de estruturas de significado é recuperada a partir de Stuart Hall e a proposição de seu modelo codificação/decodificação (HALL, 2003: 391), em que estas estruturas, de certa forma, simbolizam as referências identitárias e os repertórios culturais/estéticos dos envolvidos. A grande questão deste momento seria perceber como as mensagens sobre os espaços urbanos são reelaboradas desde o momento da recepção até o momento da produção de sentidos. Algo que é constituitivo dessa ponte, a partir do olhar teórico de Jesús Martín-Barbero, são as mediações dessa relação: as formas com que as mensagens são recebidas, relacionadas com a vivência dos indivíduos e re-apropriadas na forma de outras mensagens.

\section{Questões metodológicas}

A opção metodológica central neste trabalho é o desenvolvimento de uma dialética histórico-estrutural que nos permite uma análise historicizada e ao mesmo tempo não distante das circunstâncias estruturais do objeto. A relação histórico-estrutural teve um papel constituinte nas opções metodológicas dos estudos culturais, desde sua fase de formação e desenvolvimento, a partir do trabalho de pensadores como Edward Palmer Thompson, Raymond Williams e Stuart Hall. Houve um trânsito entre os dois paradigmas teóricos: um estruturalismo herdado do pensamento marxista, apropriado por E.P. Thompson e um culturalismo com uma característica fortemente historicizada a partir das reflexões de Williams. As duas posições estiveram em uma constante dialética (HALL, 2003: 148) e, de certa forma, foram moldando os caminhos teórico-metodológicos utilizados pela tradição britânica dos estudos da cultura, apropriada, em parte, pelo pensamento comunicacional latino-americano. Atrelado a esse modelo teórico-metodológico, opta-se pela realização de uma aproximação com o objeto a partir da combinação de algumas técnicas de pesquisa relacionadas com 
esse foco específico.

Nosso plano de trabalho será composto por dois momentos: (1) uma primeira observação com os estudantes a partir da realização de enquetes e o cruzamento destes dados com outros repertórios empíricos presentes e (2) a realização de entrevistas em profundidade com o grupo de estudantes para uma análise de maior fôlego teórico. A escolha desse procedimento não está dissociada da trajetória teórico-metodológica dos estudos da comunicação e cultura e procura apropriar práticas com uma clivagem antropológica a partir de uma intenção etnográfica para com o objeto de pesquisa. Observando as tensões presentes entre a discussão da prática etnográfica a partir de outras áreas que não a antropologia tradicional, deixamos clara nossa opção pela compreensão de uma «antropologia interpretativa», fundada a partir do pensamento de Clifford Geertz. A partir da interpretação das culturas, Geertz coloca o pesquisador em uma posição mais dialógica e decididamente específica para compreender a impossibilidade de fornecer grandes relatos sobre uma determinada sociedade, mas possibilita a compreensão de seus conflitos a partir de suas fronteiras, tensionamentos e deslocamentos. Essa posição é ressaltada por García Canclini (2006a: 142) como necessária para a compreensão das sociedades contemporâneas, sobretudo quando nos referimos aos descompassos latino-americanos.

Como este texto trata de um relato parcial de pesquisa, faremos referência aos resultados do primeiro momento de pesquisa com a realização das enquetes com os alunos e o cruzamento das falas com outros repertórios empíricos. Os repertórios são formados pelas experiências de um dos pesquisadores, que é docente do grupo de alunos, e são compreendidos como elementos de pesquisa a partir da relação de participação/observação colocada pela etnografia de caráter interpretativo. De modo que as falas dos estudantes, focadas a partir dos instantes de recepção dos espaços urbanos e da produção das mensagens, serão interpeladas, à medida do necessário, por essas experiências empíricas. A estrutura deste texto será composta pela enunciação de duas revisões teóricas necessárias ao empreendimento dos estudos: a questão dos espaços urbanos como problemática e a perspectiva das mediações para compreensão do processo a ser observado. Em um momento final traremos alguns resultados parciais que têm aqui o objetivo de nortear o desenvolvimento da pesquisa preliminar.

\section{Espaço urbano como palco de conflito}

As noções de tempo alteram-se. As dinâmicas de trabalho e lazer nas grandes cidades assumem ritmos frenéticos e descentrados. O trânsito reconfigura-se em uma impressão de contínuo caos e contínua ordem. As praças e parques não têm o mesmo uso de antigamente, não são referenciados pelas pessoas com a mesma "centralidade" que ocupavam há pouco tempo. Há dificuldade em construir meta-relatos em torno de monumentos e obeliscos. Alguns dizem que o centro das cidades está morrendo. Esses sinais empíricos, de certa forma, demonstram um panorama de crise consensual entre aqueles que se dedicam a observar as percepções do moderno. Desde o poeta Baudelaire e a figura de seu «flâneur» parisiense até os dias de hoje, observamos os espaços urbanos como sinais visíveis da crise das narrativas do progresso e da utopia tecnológica. É um fato que as estruturas que legitimavam e ordenavam o mundo estão em profundo descrédito e declínio, como nos demonstra Jean François Lyotard ao postular uma condição pós-moderna (2004). Essa condição ocorre não apenas como a supressão do antigo pelo novo, mas a partir de uma profunda problematização do presente e uma perspectiva "pluralista que aceita a fragmentação e as combinações múltiplas entre tradições, modernidade, pós-modernidade, é indispensável para considerar a conjuntura latinoamericana" (GARCÍA CANCLINI, 2006: 352). Como um dos maiores símbolos do moderno, a cidade é um desses grandes relatos que sofrem uma profunda reconfiguração em suas funcionalidades e sua organização simbólica. O espaço urbano torna-se um grande palco do conflito das estruturas da modernidade com suas próprias certezas: passamos de um local de participação pública à participação mediada pela tecnologia, que muda nossa maneira de nos relacionar e de produzir sentidos sobre o mundo. 
A trajetória das sociedades ocidentais para a modernidade, sobretudo a dos grandes centros econômicos do hemisfério norte, obedeceu, de certo modo, a um caminho bem delimitado, pois era possível perceber uma fase sucedida por outra fase, a partir das viradas simbólicas e do advento do novo e do progresso. Isso era visível para os agentes sociais que acompanharam a formação dos grandes centros urbanos a partir das inferências da técnica no cotidiano. O automóvel, o rádio, o telefone e outros inventos do século XX foram alguns exemplos das viradas simbólicas do novo como algo incontestável e realizador de uma utopia tecnológica. As mudanças espaço-temporais, causadas por essas grandes viradas, foram vivenciadas por um contingente significativo das sociedades. Como demonstra Zygmunt Bauman (2005: 28), a trajetória para a formação do Estado-nação passou justamente por essa via. Houve tempo para a formação dos grandes discursos como o do Estado-nação, o da divisão do trabalho e o do espaço urbano como ápice de seu tempo e a materialização de grandes promessas. Esse discurso sobreviveu quase incontestável a mais de um século e forneceu uma identidade nacional indelével que, segundo Bauman, "não reconhecia competidores, muito menos opositores". O próprio poeta Baudelaire, no século XIX, é uma prova da vivência radical do moderno quando seu lirismo descreve a descentralização e o deslumbramento na multidão como um "imenso reservatório de eletricidade":

O amante da vida universal entra assim na multidão como um imenso reservatório de eletricidade. Pode-se compará-lo, ele mesmo, a um espelho tão imenso quanto esta multidão; a um caleidoscópio dotado de consciência que, em cada um dos seus movimentos, representa a vida múltipla e a graça móvel de todos os seus elementos. É um eu insaciável do não-eu que, a cada instante, o manifesta e o exprime em imagens mais vivas do que a própria vida, sempre instável e fugidia.(BAUDELAIRE, 1993: 18)

A experiência do Pintor da Vida Moderna nada mais é do que uma preconização da experiência urbana que viria a ser problematizada durante todo o século XX. Jorge Larrain associa a imagem do «flâneur» à vivência vital da modernidade como uma experiência de fragmentação, mobilidade e mudança social que "não apenas rompeu com o modelo do passado, mas também foi caracterizada por um processo permanente de rupturas internas e fragmentação" (LARRAIN, 2000: 16). O relato literário traz uma experiência conectada com o que vivemos hoje no cotidiano das cidades: uma sensibilidade estética sobre as coisas, diretamente relacionada com a questão das identidades, que assumem um caráter descentrado e "insaciável". Esse episódio seria problematizado mais tarde a partir de Walter Benjamin (1989: 54), que escreveu sobre Baudelaire, na mesma condição que se colocou como um dos "primeiros a falar da metamorfose da percepção em virtude do impacto da tecnologia moderna" (SANTOS, 2003: 153).

Houve a possibilidade da percepção e mapeamento dos conflitos decorrentes da segunda metade do século $\mathrm{XX}$, que paulatinamente modificaram paisagens urbanas a partir das novas compreensões de tempo e espaço. Conforme descreve Beatriz Sarlo (2000: 14) e Martín-Barbero (2005: 289), as grandes vias de tráfego, por exemplo, que mudam as paisagens das cidades e reconfiguram a experiência urbana, nada mais são do que a emergência de um espaço de fluxos imediatos que mudam a experiência no sentido não apenas de permitir o acesso rápido, mas de permitir outra experiência de cidade por resumi-la apenas aos espaços de uso pragmático dos públicos e não interpelar seus habitantes a outros espaços de diferença e não-uso. Criam-se, a partir daí, múltiplas cidades e múltiplas noções do espaço, desde a daquele que utiliza o sistema de transporte coletivo ao que pode ter seu próprio veículo.

Tendo em vista este quadro agonístico de insatisfação com as narrativas do presente, ao situarmos a questão a partir do espaço cultural latino-americano, precisamos compreender os espaços urbanos de uma forma ainda mais problemática. Isso porque os processos de urbanização na América Latina obedeceram uma dinâmica diferente dos processos do hemisfério norte por circunstâncias históricas e caminhos diferentes. Não foi possível estabelecer uma temporalidade comum em vista de os processos de urbanização acontecerem de uma forma absolutamente descompassada. Essa perspectiva , definida como a vivência de uma modernidade tardia 
pelos países latinos, é expressa a partir do trabalho como Jorge Larraín e José Joaquín Brunner. Os dois autores chilenos contribuíram para o pensar das sociedades latino-americanas a partir de uma trajetória particular, que considera os inúmeros descompassos de temporalidade e os processos sociais a que os países foram e são submetidos. Larrain, além de ter sido um dos diretores do «Centre of Contemporany Cultural Studies» (CCCS) na cidade de Birmingham, Reino Unido, desenvolveu uma pesquisa sobre identidade cultural na América Latina através de seu livro «Identity e Modernity in Latin America» (2000). No ensaio, o autor propõe uma trajetória específica dos países latinos para a vivência do tempo moderno, evidentemente apoiada em fatos históricos politicamente comuns e também em diálogos entre as diferenças.

Larrain desdobra esse processo em cinco fases: (1) da independência até 1900, com a modernidade oligárquica atrelada aos colonizadores; (2) de 1900 até 1950, com a crise da modernidade oligárquica e a insurgência da modernização populista; (3) do pós-guerra até 1970, com a expansão das indústrias; (4) de 1970 até 1990, com o período das ditaduras; (5) de 1990 até os dias de hoje, com o neo-liberalismo e a vivência de uma modernidade tardia. O que de mais importante há nessa trajetória é justamente o fato de o autor identificá-la como específica, diferente, sobretudo na temporalidade, da narrativa moderna européia e norte-americana.

A partir dessa idéia, a modernidade latino-americana foi vivenciada em um período de tempo diferente do modelo europeu. Absolutamente não houve o mesmo tempo para vivência do moderno, e a introdução das sociedades nesse paradigma ainda está acontecendo. Os processos de independência dos países aconteceram de forma tardia e, no caso do Brasil, a transição de sociedade rural para a organização urbana e industrial efetiva, na sua totalidade, deu-se em curto espaço de tempo, a partir da segunda metade do século XX. Apesar dessa grande diferença temporal, a mesma concepção do moderno ocidental foi utilizada como paradigma político pelos países quando o modelo oligárquico entra em crise. Como ressalta o autor, essa crise acontece em concomitância com a primeira crise da modernidade européia e o crash na bolsa de valores de Nova Iorque em 1929:

But the consequences of the crisis are specific to Latin America: the oligarchic power begins to crumble, the so-called 'social question' comes to the fore, new populist regimes emerge which widen the franchise and incorporate the middle classes into government, and process of import-substituting industrialization are initiated. Thus, while in Europe a crisis of liberal is experienced, in Latin America it is the prevailing oligarchic and aristocratic export-oriented system that enters into its terminal phase, and incipient industrialization process start whit some success.(Larrain, 2000: 22)

O que se pode observar nesse contexto é um grande choque entre o tradicional das sociedades latinoamericanas e a narrativa do moderno ocorrido em um curto espaço de tempo. A análise da tensão entre tradicional e moderno é complementada através da contribuição do segundo autor chileno, José Joaquín Brunner, que propôs através de seu trabalho uma cartografia da modernidade na América Latina. Um dos primeiros pressupostos de Brunner é justamente o tensionamento entre o tradicional e o moderno não como oposição, mas como «temporalidades que coabitam» (BRUNNER, 1994: 25).

Uma das questões centrais desse olhar são as relações entre tradição e modernidade que estão presentes de forma contundente na questão urbana e influem na forma como a cidade é imaginada. Há uma imensa narrativa da cidade como legado inconteste e centro das tradições e relatos de sutura que dialoga com outras posições modernas e pós-modernas. Essa relação, longe de ser algo resolvido com a supressão de um tempo pelo outro, significa uma constante negociação entre modernidade e tradição. Isso torna-se visível a partir da paisagem urbana dos grandes centros, que conjuga construções do século XIX, nas cidades mais antigas, com grandes plantas arquitetônicas que vão modificando a paisagem simbólica de alguns bairros e impondo estilos de vida destoantes com o mapa das cidades como um imenso labirinto para o mero encontro e desencontro. Alguns dos exemplos dessa relação são casas com telhas de barro estão lado-a-lado com edifícios, prédios 
históricos são convertidos em modernos centros econômicos e tecno-igrejas e os novos planos urbanos de construção de vias para comportar o tráfego sufocante que entram em conflito com a desordem dos espaços de lazer publicamente constituídos. Há uma constante negociação entre as tradições como narrativas, os desafios do moderno e também várias concepções de tradição a partir da vivência de uma temporalidade específica na América Latina. García Canclini coloca essa idéia quando fala sobre o desdobramento do popular no moderno, no sentido de rejeitar sua simples oposição e tornar complexa essa assimetria:

O conflito entre tradição e modernidade não aparece como o sufocamento exercido pelos modernizadores sobre os tradicionalistas, nem como a resistência direta e constante de setores populares empenhados em fazer valer suas tradições. (...) Ante essa necessidade recíproca, ambos se vinculam mediante um jogo de usos do outro nas duas direções.(GARCÍA CANCLINI, 2006: 277)

Não se trata apenas do fim desta grande narrativa, mas sua constante problematização a partir da vivência da condição pós-moderna. Essa perspectiva é colocada nessa pesquisa a partir de sua condição complexificadora do cotidiano, a partir dos caminhos que oferecem autores como David Harvey e Frederic Jameson, que permitem pensar o pós-moderno no sentido de problematizar e não suplantar o tempo moderno. A partir da sensibilidade de Martín-Barbero para o tema, compreendemos que a cidade, tal como uma grande narrativa do moderno, é lugar onde essa problematização é visível em todos os seus desajustes.

Historicamente constituída, a cidade concretiza as idéias de desenvolvimento que as diferentes sociedades comportam e, com isso, faz com que suas fraturas fiquem mais expostas. A marginalização, os conflitos, a impressão de caos e ordem, o comércio informal e a circulação de produtos culturais nesses contextos são sinais de fratura social que apresentam mais complexidade do que as políticas públicas alcançariam. Nesse sentido, por exemplo, a idéia de medo presente no imaginário das cidades é apresentada por Martín-Barbero como algo que vai além da existência das ameaças da rua e está ligada a narrativa simbólica da cidade e aos pontos de coesão identitária, muito mais do que a iminência do perigo:

Medos que provém secretamente da perda do sentido de pertencer, em cidades nas quais a racionalidade formal e comercial foi acabando com a paisagem na qual se apoiava a memória coletiva, nas quais a normalização das condutas, tanto quanto a dos edifícios; levam a erosão das identidades, e essa erosão acaba roubando-nos o piso cultural, arrojando-nos ao vazio. Medos, enfim, que provêm de uma ordem constituída sobre a incerteza e a desconfiança que produz no outro, qualquer outro étnico, social, sexual - que se aproxima de nós na rua e é compulsivamente percebido como ameaça." (MARTÍN-BARBERO, 2005: 295)

Então, o tema dos espaços urbanos precisa ser compreendido a partir dessa complexidade do simbólico e do não-aparente. Boa parte dos problemas urbanos costuma ser compreendida a partir de um encadeamento aparentemente lógico: há violência porque não há emprego. No entanto, são pouco consideradas as possibilidades da violência também sustentar motivações culturais e simbólicas que vão desde a necessidade de socialização até o acesso a espaços de expressão e prática cultural dos sujeitos. Mesmo não sendo esse o foco deste ensaio, o que queremos dizer é que nossa compreensão da questão dos espaços urbanos acontece a partir da consideração deste «jogo de relações simbólicas» nas maneiras de narrar e imaginar a cidade.

\section{A perspectiva das mediações}

Martín-Barbero é referência indiscutível em estudos de recepção na América Latina. Ele foi responsável pela obra "Dos Meios às Mediações", originalmente lançada em 1987, na qual se percebe o desenvolvimento da pioneira perspectiva das mediações. Depois de passar por uma análise crítica de alguns modelos de comunicação clássicos, do reducionismo ideológico de Lasswell às concepções limitadas - embora mais consistentes - de Shannon e Weaver, e com forte ênfase na cultura e na política, o autor estabelece um 
deslocamento "dos meios para as mediações".

A proposta remete aos lugares de fala de cada pessoa, os quais demarcam uma forma particular de observar, interpretar e produzir sentido. Conforme afirma Martín-Barbero, “(...) na leitura - como no consumo - não existe apenas reprodução, mas também produção, uma produção que questiona a centralidade atribuída ao texto-rei e à mensagem entendida como lugar de verdade que circularia na comunicação" (1997: 291).

É importante averiguar, portanto, em que condições as falas estão sendo constituídas e construídas. As "posições de enunciação" (HALL, 1996) são individuais e baseiam-se em um contexto particular e, ao mesmo tempo, público, ou seja, referem-se à identidade cultural de cada pessoa - que, cabe ressaltar, consiste em um processo sempre em construção, pois interage com o social.

Sob essa perspectiva, Martín-Barbero estabelece três lugares de mediação, a saber: "a cotidianidade familiar, a temporalidade social e a competência cultural" (1997: 292). Para o autor, com relação ao primeiro caso, na América latina, as pessoas se reconhecem na televisão e, no Brasil, isso não é diferente. No entanto, para que essa situação possa ser entendida, faz-se necessário estudar o cotidiano das famílias.

O segundo caso aborda a ligação entre os tempos de produção e as rotinas cotidianas de recepção. Já o último aspecto refere-se às mais variadas bagagens culturais dos componentes da esfera receptiva (particulares, individuais), o que corrobora para um modo específico de ver/ler, interpretar e usar os produtos da cultura midiática.

Contribuindo para o desenvolvimento desta pesquisa, Orozco Gómez (2000) sinaliza cinco correntes de investigação: efeitos, usos e gratificações, criticismo literário, estudos culturais e análise crítica de audiência. Enquanto as duas primeiras identificam-se com o paradigma positivista, as três restantes têm ligações com o hermenêutico.

No cerne de seus questionamentos, a corrente dos efeitos apresenta a preocupação em saber o que acontece com os receptores expostos a uma determinada mensagem. "Que fazem os meios (ou a mensagem) com a audiência?" Conforme Orozco Gómez (2000: 53), "se admite que haja efeitos a curto, médio e longo prazo (...) há efeitos muito importantes e menos importantes (...) e uma vez que se manifestam permanecem, são irreversíveis e, outros, são momentâneos".

A corrente dos usos e gratificações inverte a questão anterior. Agora, interessa saber o que as pessoas fazem com o meio e como se apropriam dele. Isso deixa clara a noção de receptor ativo, que possui necessidades e expectativas individuais (pois variam de indivíduo para indivíduo).

Por sua vez, o criticismo literário relaciona "os estudos sobre semiótica, temática sintática e as novas correntes alemãs e francesas da estética da recepção" (OROZCO GÓMEZ, 2000: 56). Esse modelo tem como objetivo saber o que é produzido a partir do contato entre um leitor e um texto. Já os estudos culturais indagam qual a função da cultura na interação meio-mensagem-audiência (OROZCO GÓMEZ, 2000). A cultura é o centro, o lugar onde perpassam as relações de poder. A comunicação não se entende fora da cultura. Logo, pretende-se saber como intervém a cultura na interação mídia/receptor.

Portanto, sendo ativo e dono de uma cultura particular, o receptor produz códigos culturais nos seguintes modelos: na reprodução, em que aceita tudo o que recebe, o que o constitui em uma espécie de cúmplice do pensar hegemônico; na negociação, quando aceita algumas partes daquilo a que está exposto e outras não; e na resistência, processo em que não se aceitam as propostas de sentido oriundas da mídia, o que acarreta uma produção alternativa ou contraproposta. Para Orozco Gómez, a possibilidade reinante no processo de 
recepção dos meios é a negociação (2003) (1).

A última corrente - a análise crítica de audiência - implica estudar os meios culturalmente. É feita uma abordagem completa da audiência. O receptor é o elemento principal. A interação com o meio consiste em um processo muito complexo em que interagem diversos elementos como o meio, a mensagem, a interação, o receptor, a cultura, o sistema social, o discurso do receptor etc. $(2000 ; 2003)$.

Na concepção de Orozco Gómez, a perspectiva das mediações implica levar em conta toda uma soma de fatores que podem causar influência no processo de produção de sentido dos receptores, tais como a identidade particular de cada um, a família, a escola, o grupo de amigos, o bairro, o trabalho, a cidade, os meios de comunicação e a disposição dos indivíduos frente a eles, seu nível de instrução, sexo, idade, etnia, religião, salário, classe social, ideologia etc.

Assim, através dessa identidade construída - e jamais acabada -, o receptor produzirá significados próprios, particulares e individuais. A total apropriação, a negociação ou até mesmo a resistência plena das mensagens são decorrentes diretas das diferentes mediações anteriormente citadas. Nessa realidade complexa em que atuam diferentes fontes e origens, a cultura é eleita "a grande mediadora de todo processo de produção comunicativa” (OROZCO GÓMEZ, 2000: 114). Portanto, a comunicação vai além dos meios; ela desloca-se para as mediações, que, por sua vez, são permeadas pela cultura. Assim, todos os processos sociais são perpassados pela cultura. Ela é o agente de mediação.

Essas mediações concretizam-se em três práticas (OROZCO GÓMEZ, 1993; 2000): a sociabilidade (formas de negociação, de contato com os outros; práticas cotidianas de interação), a ritualidade (ligada às rotinas "repetição de certas práticas") e a tecnicidade (cada meio possui uma singularidade que se remete ao suporte técnico).

Em sintonia com a proposta metodológica desta pesquisa, segundo Orozco Gómez (2000: 83), a investigação qualitativa "é um processo de indagação de um objeto ao qual o investigador alcança através de interpretações sucessivas com a ajuda de instrumentos e técnicas, que lhe permitem envolver-se com o objeto para interpretá-lo da forma mais integral possível". Ao contrário de antes, quando o instrumento de trabalho e a(s) técnica(s) utilizada(s) guiavam a trajetória da pesquisa, agora há decisões que vão sendo tomadas durante o período de investigação. O líder é o sujeito investigador. Afirma-se, então, que a presente pesquisa não possui a pretensão de ser uma estrutura fechada, acabada. Pelo contrário, está aberta a eventuais mudanças de rumo ao longo de sua caminhada.

Com relação ao tamanho da amostra, por experiência própria embasada em anos de pesquisa, Orozco Gómez (2000) afirma não ser necessário entrevistar mais do que 25 pessoas, pois, além desse número, as informações novas obtidas são mínimas. Para o autor, um número entre 10 e 20 entrevistados pode ser suficiente para que se obtenha conhecimento, pois não interessa a quantidade, mas, sim, como se desenvolve o processo crítico dos receptores.

Pretendendo detectar posicionamentos, a proposta desta pesquisa ganha força na metodologia qualitativa de investigação de Orozco Gómez (2000: 2003). Não há o interesse, aqui, de generalizar os resultados, mas, sim, verificar (não no sentido quantitativo) possibilidades e anseios com base em uma amostra limitada.

\section{Considerações parciais e vetores de pesquisa}

Nesta parte, iremos fornecer algumas considerações parciais sobre a pesquisa sobre recepção de espaços urbanos com os alunos do curso de cinema e animação da UFPel. É digno de nota que estes direcionamentos têm o caráter exclusivo de apontar vetores para o seguimento deste estudo e são resultado de uma primeira 
aproximação com o objeto de pesquisa tal como explicamos nos procedimentos metodológicos. Não existe a intenção de oferecer uma análise aprofundada. Nossa preocupação neste momento é fornecer direções para a pesquisa mais do que propriamente materializar reflexões. O repertório que compõe esta parte é composto pela realização de enquetes com seis estudantes participantes do projeto e o cruzamento com algumas experiências empíricas, conforme especificado no início do texto. $\mathrm{O}$ foco das enquetes com os estudantes foram os momentos de recepção dos espaços urbanos e a realização das mensagens com relação à produção de sentidos sobre a cidade de Pelotas. Cabe ressaltar também que o contato prévio com a discussão do tema permitiu certa sensibilidade teórica para perceber alguns vetores potenciais, que procuramos elencar a partir deste momento.

\section{O referencial do passado e o diálogo entre tradicional e moderno}

Algo recorrente na observação dos relatos dos estudantes são os referenciais no passado para a descrição do espaço urbano. Essa consideração não pode ser vista como ocasional se observarmos empiricamente o contexto da cidade de Pelotas. Com mais de 200 anos, a cidade foi uma das primeiras do Estado e possui um grande conjunto arquitetônico de prédios históricos que caracterizam seu espaço urbano. Historicamente, especialmente durante o ciclo do charque que perdurou até o início do século XX, o município foi um dos principais centros econômicos da região sul. Essa dinâmica influenciou boa parte da organização do espaço urbano e da arquitetura dos prédios de estética erudita em vista da influência européia. Mesmo sem uma observação mais aprofundada sobre este tema, é oportuno observar que a atenção à questão histórica foi recorrente em quase todas as falas dos estudantes. E essa questão, em boa parte das falas, não se encontra essencializada: está sempre posta em conflito com outros posicionamentos ligados à interpelação do moderno.

Temos avenidas inacabadas ou com trajeto alterado por conveniências alheias ao bem público. As quais poderiam liberar o centro histórico da cidade para que este pudesse ser desenvolvido. Temos atividades comerciais, aqui cito os camelôs, inadequadas para qualquer cidade grande, dia a pós dia matando os poucos empresários locais que ainda investem na cidade(Wagner Oliveira).

A cidade e Pelotas é um local no qual um passado importante impera, ao passo de que as pessoas que nela vivem acabam perdendo-se no sentido de que não sabem o que fazer primeiro, valorizar a história, ou tentar construir o futuro (Leonardo Peixoto).

Nesses dois casos é possível ver como se materializa a problemática do diálogo entre tradição e modernidade. García Canclini trata dessa questão como um "jogo de usos" (2006: 277), uma assimetria que continua existindo entre as duas posições, mas de maneira mais intricada e complexa. O jogo de usos não coloca os dois posicionamentos como uma simples oposição binária, mas compreende certo dialogismo entre as duas posições. Ambas estão em constante conflito, mas precisam negociar uma com a outra, compartilhar a mesma temporalidade e encontrar uma lógica de desenvolvimento. Com a intenção de traçar possibilidades, percebemos que as questões históricas encontram-se sempre em conflito por conta da relação intricada entre tradicional e moderno, o que exime que sejam compreendidos «sobre o mesmo tempo» e não como a supressão de um tempo pelo outro.

No relato do estudante Wagner Oliveira é possível perceber alguns indícios de uma das principais fraturas da modernidade tardia vivenciada pelos países da América Latina, a partir do comércio informal em negociação com o espaço urbano. Como demonstra Jorge Larrain (2000: 199), o comércio informal é um dos sinais para compreensão da trajetória específica latino-americana no momento em que tem raiz na não-existência de um Estado-nação capaz de regular o sistema econômico que comporte os trabalhadores. Já no segundo relato, do estudante Leonardo Peixoto, o conflito entre o tradicional e o moderno está explícito e relacionado pelo próprio estudante à necessidade de se pensar o futuro a partir do passado. E o espaço urbano é o lugar onde esses desajustes são materializados e percebidos pelos agentes sociais. Aí reside o interesse deste estudo. 


\section{Espaços urbanos e mediações}

Outro indício que pode apontar um caminho para o desenvolvimento da pesquisa é a questão das mediações no espaço urbano a partir do relato dos estudantes. Essa perspectiva abriu-se, especialmente, a partir da circunstância de produção de sentidos sobre os espaços quando os estudantes perceberam que era possível fornecer seus próprios relatos e suas próprias vivências sobre determinados espaços urbanos. O projeto "Olhares" foi compreendido por alguns sobre essa perspectiva de oferecer diferentes formas de leituras dos espaços e uma das experiências mais agradáveis apontadas por eles foi a de observar a percepção dos outros colegas sobre espaços comuns.

A história contada de cada local esquece, invariavelmente, dos detalhes e das histórias particulares vividas enquanto tal ou tal período econômico acontecia ou quando algum prefeito construia uma ponte. Este documentário busca mostrar de forma mais natural o que a cidade de Pelotas é hoje, o que ela instiga nos seus cidadãos (Leonardo Peixoto).

Em um documentário no formato do olhares é interessante ver que há diversos modos de ver as coisas, que cada um tem seu modo único de interpretar o lugar retratado(Diego Souza).

Mesmo sendo uma visão particular de cada um dos participantes, as imagens ali contidas representam a cidade de Pelotas e são um documento, contendo a visão e a opinião de estudantes, sobre partes da cidade onde moram(Fábio Sinoti).

Percebe-se a priori que a prática de registrar o espaço urbano permite sua codificação a partir de uma parcialidade que, ao invés de restringir seu sentido, fornece várias parcialidades sobre um mesmo espaço partilhado pelos estudantes. Cada percepção cria pequenos olhares ao invés de um grande meta-relato. Os pequenos relatos são importantes se oferecidos como uma forma de narrar a cidade "de uma forma mais natural", como coloca o estudante Leonardo Peixoto, numa perspectiva que deve ser melhor problematizada. O aporte teórico das mediações, fornecido por Jesús Martín-Barbero, pode fornecer uma sensibilidade teórica adequada ao desenvolvimento desse vetor de pesquisa.

\section{Bibliografia:}

BAUDELAIRE, Charles. O pintor da vida moderna. Lisboa: Vega, 1993.

BAUMAN, Zygmunt. Identidade. Rio de Janeiro: Zahar, 2005.

BENJAMIN, Walter. Charles Baudelaire: um lírico no auge do capitalismo. $3^{\mathrm{a}}$. ed. São Paulo: Brasiliense, 1994.

BRUNNER, José Joaquín. Cartografias de la modernidad. Santiago Chile: Dolmen Ediciones, 1991.

GARCÍA CANCLINI, Néstor. Diferentes, desiguais e desconectados: mapas da interculturalidade. Rio de Janeiro: UFRJ, 2006.

. Culturas híbridas: estratégias para entrar e sair da modernidade. São Paulo: Edusp, 2006.

HALL, Stuart. Da Diáspora. Identidades e Mediações culturais. Org. Liv Sovik. Belo Horizonte: UFMG / Brasília: UNESCO, 2003.

Identidade Cultural e Diáspora. In: Revista do Patrimônio Histórico e Artístico Nacional. V. 24, 1996a, p. 68-76.

JOHNSON, Richard. O que é, afinal, estudos culturais? 3ª ed. Belo Horizonte: Autêntica, 2004.

LARRAIN, Jorge. Identity and Modernity in Latin America. Cambridge: Polity Press, 2000.

LYOTARD, Jean-François. A condição pós-moderna. 5ª ed. Rio de Janeiro: José Olympio, 2004.

MARTÍN-BARBERO, Jesus. Dos meios às mediações: comunicação, cultura e hegemonia. Rio de Janeiro: UFRJ, 1997.

Loyola, 2005.

Ofício de cartógrafo: travessias latino-americanas da comunicação na cultura. São Paulo:

OROZCO GÓMEZ, Guillermo. Dialéctica de la mediación televisiva - Estruturación de estrategias de 
recepción por los televidentes. Análisi. Barcelona, nº 15, 1993, p. 31-44.

. La investigación en comunicación desde la pespectiva cualitativa. Buenos Aires: Universidad Nacional de La Plata, 2000.

Tel-E-Videncias - Metodologias qualitativas de investigação em comunicação, audiências e meios audiovisuais. Seminário. Porto Alegre, PUC-RS, 2003.

SANTOS, Laymert Garcia dos. Politizar as novas tecnologias O impacto sócio-técnico da informação digital e genética. São Paulo: Editora 34, 2003.

SARLO, Beatriz. Cenas da vida pós-moderna. Rio de Janeiro: Editora UFRJ, 2000.

\section{Notas:}

Este artigo foi apresentado no IX Seminário Internacional da Comunicação realizado em 2007 na Pontifícia Universidade Católica do Rio Grande do Sul.

(1) Esta categorização do sujeito receptor assemelha-se muito àquela desenvolvida por Hall (1980). No entanto, ao invés de "reprodutor", Hall utiliza "dominante"; no lugar de resistência, este usa o termo "oposição". O termo "negociação" é trabalhado pelos dois autores.

\section{Mini Currículo :}

Fábio Souza da Cruz - Doutor em Comunicação Social pela Pontifícia Universidade Católica do Rio Grande do Sul. Docente da Universidade Católica de Pelotas (ECOS/UCPel). E-mail: fabiosouzadacruz@gmail.com

Guilherme Carvalho da Rosa - Mestre em Comunicação Social da Pontifícia Universidade Católica do Rio Grande do Sul. Docente da Universidade Federal de Pelotas (IAD/UFPel). E-mail: guilherme.rosa@vetorial.net 